\title{
Enhanced Permeability of Biological Tissue Following Electric Field Treatment and Its Impact on Forced Convection Dehydration
}

\author{
Bessadok-Jemai A., Khezami L., Hadjkali M. K., and Vorobiev E.
}

\begin{abstract}
Impact of an electric field treatment (PEF) on tissue permeability has been studied based on the kinetics of dehydration of biological particles (ex. Shredded carrots). The moisture loss kinetics of the particles placed in a closed chamber, have been studied based on continuously measured relative humidity $(\Delta \Phi)$ of circulating air. The apparatus could be used for the subsequent pressing/PEF treatment operation and air circulation. Using two thermo-hygrometers, the continuous measurements of the relative humidity difference between entering and exiting air, were used in a normalized form to follow the kinetics of water loss for various air speed and and/or following PEF treatment. Commonly, several kinetic models may be correlated with experimental data, i.e. Fickian, Page's, and empirical types. These correlations showed that Page's type model, which is characterized by drying speed ( $k$ in min-1) and time exponent (n), is best suited for this type of tissue (exhibiting shrinkage). The effect of an electric field pre-treatment on humidity transport within the particles was also illustrated using this experimental setup. An increased permeability of the tissue resulted in about $20 \%$ drying time reduction following PEF pretreatment compared to drying without PEF.
\end{abstract}

Index Terms-Biological particles processing, electric fields, modeling moisture loss kinetics, forced convection relative humidity, page's model.

\section{INTRODUCTION}

Dehydration by way of drying is a major operation in food processing which often consumes significant quantities of energy. Dehydrated foods which are widely used, are stable under ambient conditions, less costly transported, and can be easily incorporated during food formulation and preparation. The drying process is used either as primary operation for preservation, or as secondary process in certain product confectioning operations.

In general, the mechanism of dehydration by way of drying is studied by monitoring the water loss of the dried food

Manuscript received January 24, 2015; revised May 10, 2015. The experimental work has been realized in the University of Technology of Compiegne (UTC-France) (TAI-team). This work was partly supported by the National Plan for Science, Technology and Innovation (MAARIFAH), King Abdulaziz City for Science and Technology, Kingdom of Saudi Arabia, Award number (11-NAN-1879-02).

Bessadok-Jemai A. and HadjKali M. K. are with the King Saud University, CoE-CHE, P.O. Box 800 Riyadh 11421- KSA (e-mail: abessadok@ksu.edu.sa, mhadjkali@ksu.edu.sa).

Khezami L. is with Al Imam Mohammed Ibn Saud University, Faculty of Sciences-Department of Chemistry P.O.Box: 90950 Riyadh: 11623-KSA (e-mail:1khezami@gmail.com).

Vorobiev E. is with the University of Technology of Compiegne, Chemical \& Industrial Process Engineering Department Compiegne, France (e-mail: Vorobiev.Eugene@utc.fr). versus time as well as process parameters such as the pre-treatment, the mode of drying, experimental device, temperature, air flow-rate, and geometry of particles [1]-[3]. When these parameters are adequately set, the evolution of the mass of the samples can be obtained in a continuous way without interrupting the drying operation. Nevertheless, in a significant number of works dealing with the mechanism of drying, to insure adequate weighing without disturbance, it is necessary to periodically stop the procedure or to extract one or more samples in order to separately determine the weight in the course of time [4]-[9].

In a number of situations, the experimental apparatus itself does not allow to discontinuously weigh the samples. In fact, technical solutions required by the equipment construction to take advantage of some functionalities, make discontinuous measurements more difficult to realize [10]. In addition, establishing kinetics of drying in a discontinuous way requires a considerable number of test runs (the number of points of measurements multiplied by the numbers of repetitions), in comparison with a method of a continuous measurement.

In the present work, a method to monitor the kinetic of drying of a fixed bed of particles has been established uninterruptedly without having to stop tests. The drying kinetic is in fact based on continuous measurements of relative humidity of a drying air at the inlet and the outlet of a filter-press. A number of discontinuous measurements of the mass of the samples was carried out to validate the adopted method. Generally, the drying curves can be modeled using several kinetic models such as Fickian, Page's, and empirical types [1], [2], [11]-[13]. In the present work, only the Page's type model will be considered as it has been previously found to best suit drying kinetics for high water content agro-food particles [11]-[13].

\section{MATERIALS AND METHODS}

\section{A. Tested Material}

Carrot roots purchased from a local supermarket constituted the test material. Prior to each experiment, the carrots samples are subjected to two controls: i) quantitative control: in which the dry matter is determined by means of an infrared desiccator (SMO 01, Scaltec), and ii) qualitative control, in which a visual appreciation of the product state is done (rigid or soft aspect, appearance of molts). Before filling the apparatus, the roots of carrot are reduced in small particles (grating type) having a length varying from 3 to 4 $\mathrm{cm}$ and a cross section of about $2 \mathrm{~mm} 2(1 \times 2)$. The drying runs are carried out with $(30 \pm 2 \mathrm{~g})$ of particles. 


\section{B. Drying Apparatus}

The tests are carried out in an experimental unit of laboratory, allowing at the same time the electric treatment (P.E.F) and also the drying of the product. A detailed diagram of this unit is presented in Fig. 1. The unit is essentially made-up of a cell of drying, an electric generator of pulsed electric field and of a microcomputer allowing the command and the acquisition of the data.

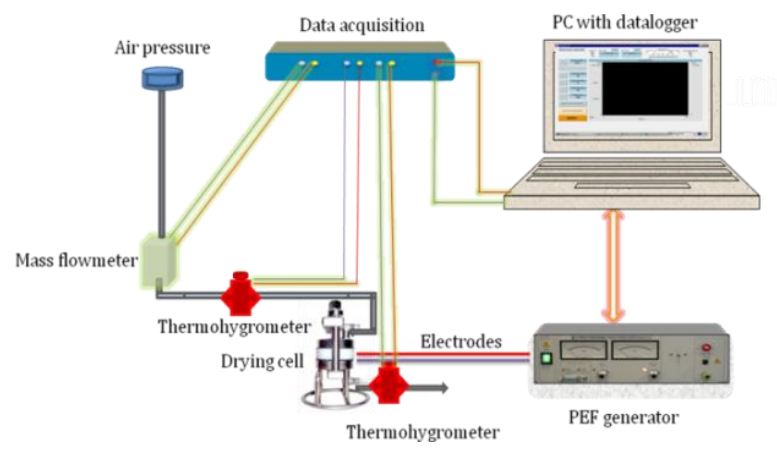

Fig. 1. The experimental drying unit diagram.

The drying chamber is a lab scale cell made-up of a polypropylene framework comprising a cylindrical cavity, two metal plates, a rubber diaphragm (for pressure delivery) and two stainless steel electrodes. The internal cross sectional surface provided to drying is about $25 \mathrm{~cm}^{2}$. Sealing of the entire the filter-press chamber is ensured by two O-rings placed between the plates and the frame (Fig. 2).

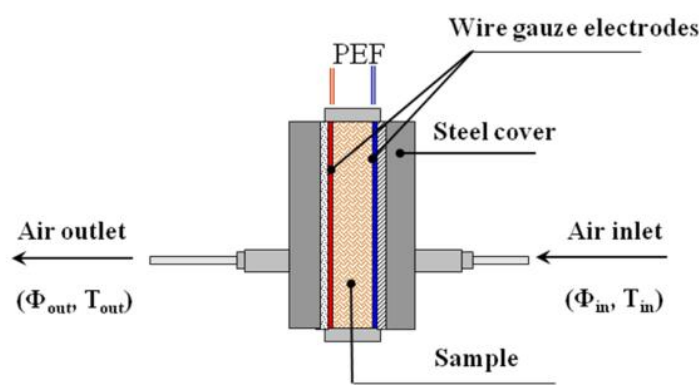

Fig. 2. The drying cell.

The perforated electrodes allow an adequate distribution of drying air through the particles bed. The pressure and the flow-rate of the drying air circulating in experimental device are adjustable respectively from 0 to 12 bars and from 0 to 100 $1 /$ min starting from the network of the compressed air. The control of the pressure is ensured by means of a commercial pressure reducer. The air flow-rate is detected on a digital mass flowmeter (AALBORG GEC47).

The relative humidity $\Phi$, and the temperature are measured by two hygrometers, (Testo645, Germany), assembled at the input and at output of filter-press. These various elements, namely, the mass flowmeter, the thermo-hygrometers and the balance are connected to a control and acquisition system allowing continuous acquisition of different parameters by the same program developed on the operating system HPVEF 3.2 , as well as the control of the generator of PEF.

\section{Modeling the Drying Kinetics}

Simultaneous measurement of the humidity of the drying air, at the inlet $\left(\Phi_{\text {in }}\right)$ and at the outlet $\left(\Phi_{\text {out }}\right.$ ) of the filter-press, are first of all used to obtain the evolution of the difference between these two values versus time:

$$
\Delta \Phi(t)=\Phi_{\text {out }}-\Phi_{\text {in }}=f(t)
$$

The integral under the curve of this evolution is calculated then dropped versus time and described as follows:

$$
I_{\Delta H R}=\int \Delta \Phi(t) \cdot d t
$$

The integral $I_{\Delta \Phi}$ is computed cumulatively for all the duration of drying. To some extent, it is proportional to the water loss of the sample, thus, normalizing this integral may be assimilated to the normalized mass of the sample:

$$
M N^{*}=\frac{I_{\Delta \Phi}-I_{\Delta \Phi}^{\infty}}{0-I_{\Phi R}^{\infty}}=\frac{m(t)-m_{\infty}}{m_{o}-m_{\infty}}
$$

Knowing the initial $\left(m_{0}\right)$ and the final $\left(m_{\infty}\right)$ masses of the particles, the kinetic of drying can be deduced from the equation (3) as follows:

$$
m(t)=\left(m_{o}-m_{\infty}\right) \cdot M N^{*}+m_{\infty}
$$

In order to compare the drying kinetic parameters for pulsed electric filed treated samples and control ones, Page's type model has first been used and fitted to experimental data [14]. The general model is as follows:

$$
M N^{*}=\sum A_{i} \cdot e^{-\lambda^{2} \cdot(k \cdot t)^{n}}
$$

where the main parameters are :

$k:$ is the rate coefficient $(1 / \mathrm{s})$,

$n$ : is a parameter characterizing the material used.

$$
A_{i}=8 /((2 i+1) \cdot \pi)^{2} \text { and } \lambda_{i}=((2 i+1) / 2 \cdot \pi)^{2} ; i=1 . .5
$$

A Fickian type model can then be considered as a special case of Eq. (5) when $n=1$.

\section{RESULTS AND DISCUSSION}

The variations of the difference, $\Delta \Phi$, and the integral, $I \Delta \Phi$, during drying times, are depicted in Fig. 3(a). The filter-press is air-tight, so that, the measured difference $\Delta \Phi$ represents the quantity of water given off by the particles to the drying air. The normalized form of the integral, $I \Delta \Phi$ versus time, $M N^{*}$ is presented in Fig. 3(b). The standardized form is then used to deduce the evolution of the mass of bed of particles during drying using the initial and final masses (Fig. 4).

This evolution suits perfectly the evolution of the mass observed in the case of discontinuous experiments, based on the measurement of the masse of the dried sample with a mean relative percentage deviation of about $5.38 \%$. The treatment of the results of drying in terms of absolute moisture instead of the relative moisture, at ambient temperature, does not mark a significant deviation compared to the discontinuous measurements. The continuous line in Fig. 4, show the calculated mass variation versus drying time deduced from absolute moisture and shows quite a good agreement with the corresponding relative humidity values. 

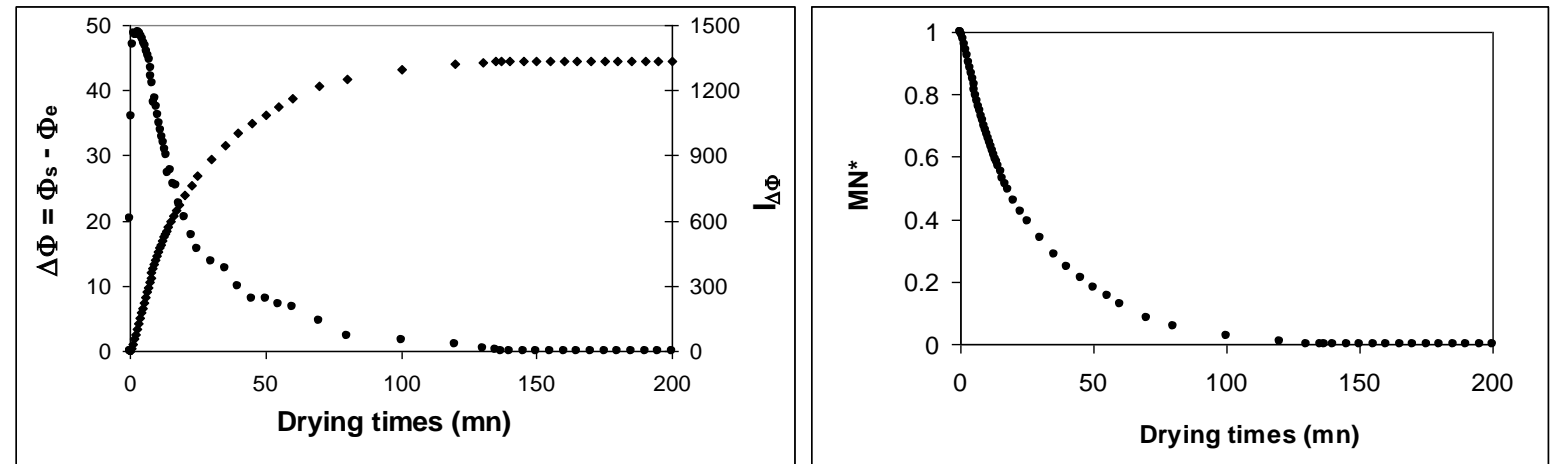

Fig. 3. (a) Integral under the curve of $\Delta \Phi=f(t)$ and (b) standardized form of the integral, $I \Delta \Phi$, for a dry air flow-rate of about $47.31 / m n$ at ambient temperature.

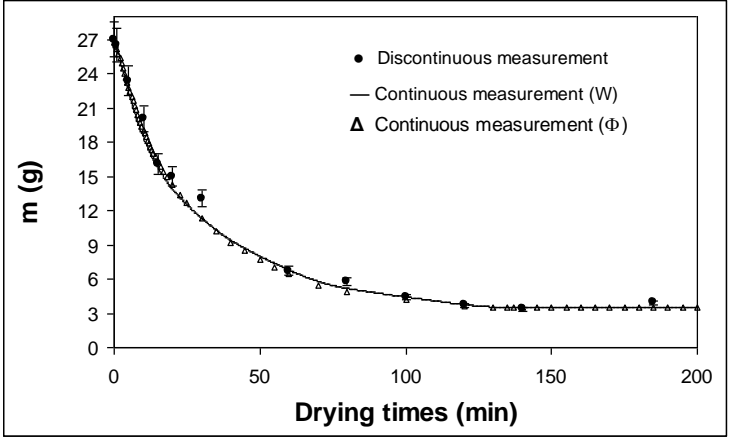

Fig. 4. Evolution of mass of the fixed bed carrot particles versus drying time for a dry air flow-rate of about $47.3 \mathrm{l} / \mathrm{mn}$ at ambient temperature; $(\Delta)$ continuous measurement based on $\Phi(\%),(-)$ continuous measurement based on $\mathrm{W},(\bullet)$ discontinuous measurement.

The curve obtained by continuous measurements results from the average of three tests of approximately 3 hours each one (about one day of tests). This illustrates the interest of uninterrupted measurements which require definitely less time of tests to obtain equivalent results (need two to three days of discontinuous measurements).

The experimental device could be used to study the effect of air flow on the kinetic of drying of the vegetable particles inside the cell. As shown above in Fig. 5 (a)\&(b), an increase of the velocity of drying is obtained by increasing the air flow. Moreover, the representation of the results while being on $\left(-d M N^{*} / d t\right)=\mathrm{f}\left(M N^{*}\right)$, revels a characteristics behavior of the agro-alimentary products (i.e. structural deformation hindering drying, hardening of the particles external layer in contact with drying air...) [4]-[6].

The effect of an electric pre-treatment by a PEF was realized in same experimental device. The PFE pre-treatment was applied in a similar manner with respect to an experimental optimization done in a previous study [14]-[16]. The drying process, carried out at ambient temperature under an air flow-rate of about $10 \mathrm{l} / \mathrm{min}$, showed a great potential of a PEF pre-treatment to enhance water diffusivity.
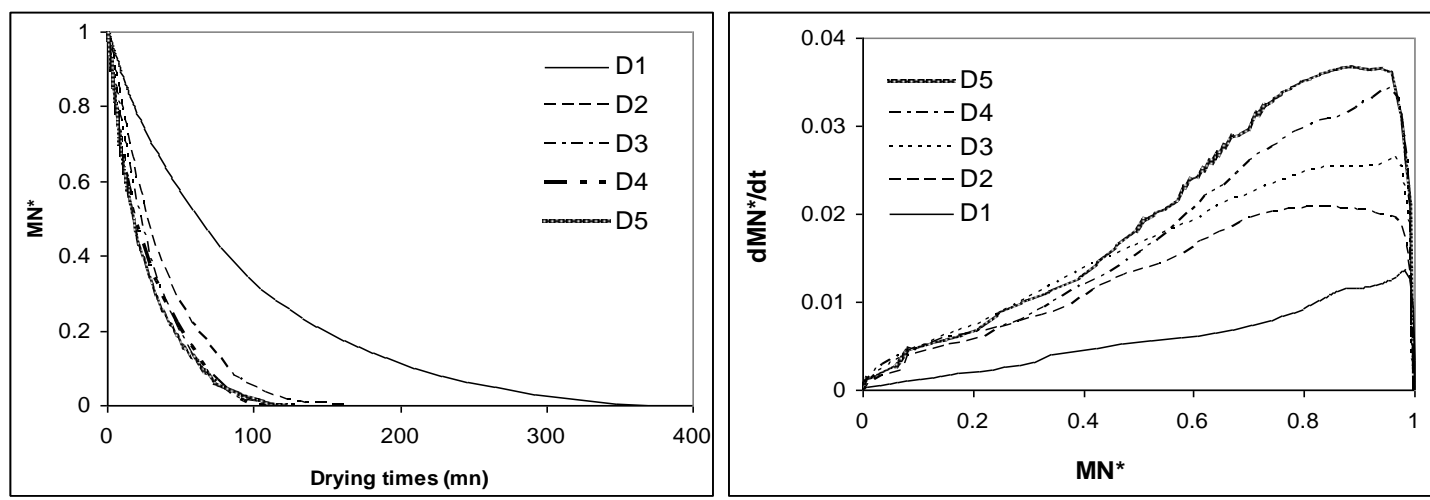

Fig. 5. Drying kinetic of carrot particles versus dying time (a) and drying rates versus normalized moisture content (b) for different dry air flow-rate at ambient temperature; D5 = 47.3 1/mn, D4 = 37.75 1/mn, D3 = 28.83 1/mn, D2 = 19.7 1/mn and D1 = $11 \mathrm{l} / \mathrm{mn}$.
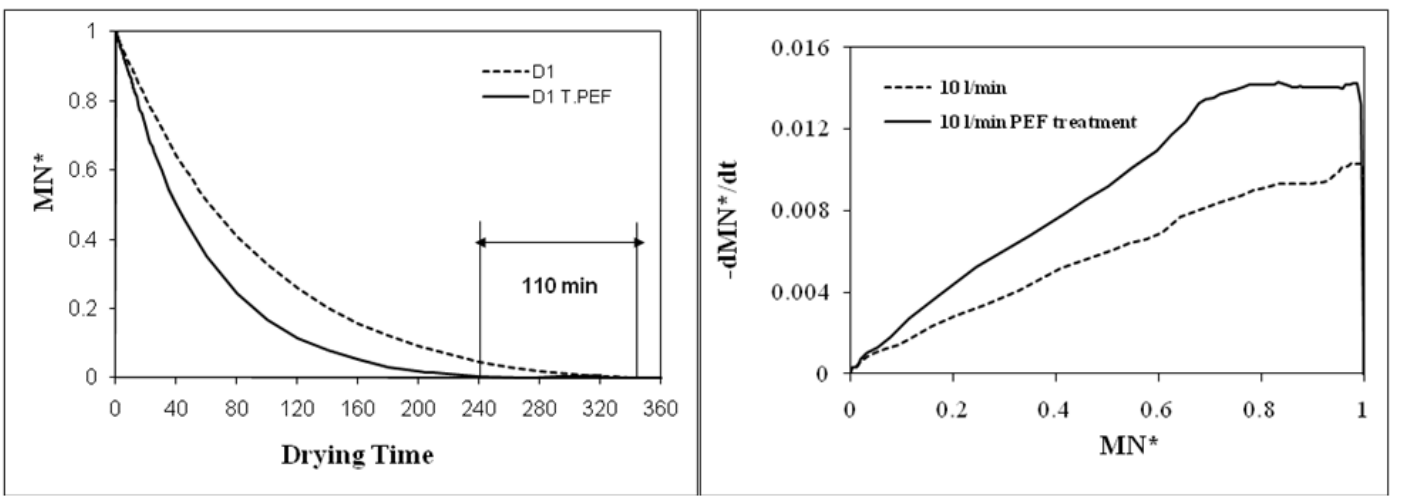

Fig. 6. PEF pre-treatment effect on drying kinetic (a) and drying rates (b) of an air flow-rate of about $11 \mathrm{l} / \mathrm{mn}$ at ambient temperature: (...) untreated samples, (一) treated samples. 
The drying kinetics of carrot pulps was significantly improved (Fig. 6(a)) and the drying time was decreased of what about 110 minutes (about 20\% time reduction). Furthermore, the plot of drying rate versus moisture content reveals that a significantly higher rate is initially obtained combined with a longer constant rate period.
As can be seen from Table I, the PEF treatment had a significant effect on the rate coefficient $\left(4.95 \times 10^{-4}\right.$ compared to $3.21 \times 10^{-4}$ ) corresponding to about $54 \%$ increase. The power (n) didn't seem to vary since it mainly characterizes the tissu (carrot here).

TABLE I: Page's Type Model Parameters ObTained From Matlab@C Curve FitTing ToOlbox

\begin{tabular}{|c|c|c|c|c|}
\hline & Constants & Value & 95\% conf. Interval & $\overline{\mathbf{R}^{2}}$ \\
\hline & $A_{i}^{\delta}$ & $8 /((2 i+1) \cdot \pi)^{2} ; i=1 . .5$ & & \\
\hline \multirow[t]{4}{*}{ Untreated samples } & $i$ & $((2 i+1) / 2 \cdot \pi)^{2} ; i=1 . .5$ & & 0.997 \\
\hline & $k^{n}$ & $3.207 \times 10^{-4}$ & $(2.398$ to 4.017$) \times 10^{-4}$ & \\
\hline & $n$ & 1.521 & (1.464 to 1.579$)$ & \\
\hline & & Same as above & & \\
\hline \multirow{2}{*}{$\begin{array}{l}\text { PEF-treated } \\
\text { samples }\end{array}$} & $k^{n}$ & $4.952 \times 10^{-4}$ & $(3.719$ to 6.186$) \times 10^{-4}$ & 0.996 \\
\hline & $n$ & 1.587 & (1.519 to 1.654$)$ & \\
\hline
\end{tabular}

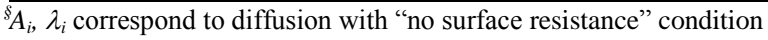

\section{CONCLUSION}

This paper is a part of a study concerning the impact of an electric treatment with a PEF on the drying kinetics of agro-alimentary products. The objective of this study was to validate the means of measurements and experimental device of drying and use it to analyze the effect of PEF treatment on the drying kinetics. The measurement technique was validated by a series of tests in which drying is stopped in order to be able to dismount the cell and to weigh the samples. For instance, for a given flow-rate, one day of tests is enough to obtain the kinetics of drying (the average of three tests) compared with more than three days of tests with the discontinuous method and for the same conditions of drying. This illustrates well the saving of time carried out without incidence on the precision of measurements.

The present method allowed to detect a positive effect of forced convection and PEF pretreatment on the drying kinetics. For instance, about $20 \%$ reduction in the drying time was achieved following a PEF pretreatment. Furthermore, PEF treated samples were characterized by a significantly higher initial drying rate combined with a longer constant rate period. Modeling the kinetics of drying by Page's type model revealed that the drying rate may be increased by more than $50 \%$ following a PEF treatment.

\section{ACKNOWLEDGMENT}

This work was supported in part by the National Plan for Science, Technology and Innovation (MAARIFAH), King Abdulaziz City for Science and Technology, Kingdom of Saudi Arabia, Award number (11-NAN-1879-02).

\section{REFERENCES}

[1] C. M. Land, Industrial Drying Equipment: Selection and Application, Marcel Dekker Inc., New York, 1991.

[2] A. S. Mujumdar, Handbook of Industrial Drying, Marcel Dekker; Inc., New York, 1987

[3] J. P. Nadeau and J. R. Puiggali, Sechage, Des Processus Physiques Aux Procedes Industriels, Edition Lavoisier, Paris, 1995.

[4] L. Khezami, A. B. Jemai, R. Capart, and E. Vorobiev, "Drying Kinetics Study Of Food Pulps By Continuous Relative Humidity Measurements: Air Flowrate And Electric Field Effects," Chem. Technol., vol. 5, no. 1, pp. $45-50$, June 2010 .
[5] W. A. M. McMinn and T. R. A. Magee, "Principles, methods and applications of the convection drying of foodstuffs," Trans. of the IChemE, vol. 77, pp. 175-193, 1999 .

[6] W. Sahyoun, "Maîtrise de L'aptitude des Matériaux Agro-alimentaires aux Procèdes de Séchage,' PhD Thesis, Dept. Industrial Processes Eng. Univ. of Tech. of Compiegne, France, 1996.

[7] W. Sendeera, B. Bhandari, G. Young, and B. Wijesinghe, "Physical properties and fluidization behaviour of fresh green bean particulates during fluidized bed drying," Trans. Of the IchemE, vol. 78, pp. 43-47, 2000 .

[8] C. Suarez and P. Viollaz, "Shrinkage effect on drying behaviour of potato slabs," Journal of Food Engineering, vol. 13, pp. 103-114, 1991.

[9] J. C. Ho, S. K. Chou, A. S. Mujumdar, M. N. A. Hawlader, and K. J. Chua, "Optimization framework for drying heat-sensitive products," Applied Thermal Engineering, vol. 21, pp. 1779-1798, 2001.

[10] H. Bouzrara and E. Vorobiev, "Beet juice extraction by pressing and pulsed electric fields,' International Sugar Journal, vol. 102, pp. 194-200, 2000.

[11] A. B. Jemai, "Characterizing the drying kinetics of high water content agro-food particles exhibiting non-fickian mass transport," Chemical Engineering Transactions, vol. 32, pp. 1759-1764, 2013.

[12] M. Zielinska and M. Markowski "Air drying characteristics and moisture diffusivity of carrots," Chemical Engineering and Processing, vol. 49, pp. 212-218, 2010.

[13] I. D. Veleşcu, I. Țenu, P. Cârlescu, and V. Dobre. "Convective air drying characteristics for thin layer carrots," Bulletin UASVM Food Science and Technology, vol. 70, no. 2, pp. 129-136, 2013.

[14] H. Bouzrara, "Amelioration du pressage de produits vegetaux par champ electrique pulse," These al.UTC, Compiegne, 2001.

[15] A. B. Jemai and E. Vorobiev, "Pulsed electric field assisted pressing of sugar beet slices: towards a novel process of cold juice extraction," Biosystems Engineering, vol. 93, no. 1, pp. 57-68, 2006.

[16] E. Amami, L. Khezami, E. Vorobiev, and N. Kechaou, "Effect of pulsed electric field and osmotic dehydration pretreatment on the convective drying of carrot tissue," Drying Technology, vol. 26, pp. 231-238, 2008.

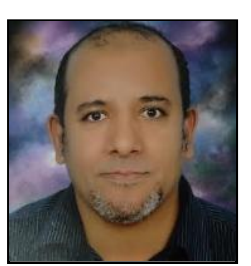

Abdelbasset Bessadok-Jemai was born in Gabès, Tunisia on March $7^{\text {th }} 1965$. He received a BME degree in March 1990 and MSc degree in September 1991 from the Georgia Institute of Technology (Atlanta, USA). He then earned an MSc degree from September 1992 and a PhD degree in June 1997 degrees in Industrial Process Engineering from the University of Technology of Compiegne (France).

He held a teaching and research assistantship for two years in the University of Technology of Compiegne in addition to few years as a research associate in novel food processing technologies. In 2003, he was appointed as an assistant professor in the Higher Institute of Applied Sciences and Technology, Department of Industrial Chemistry and Processes (ISSAT Gabès-Tunisia). Since the fall of 2010, he joined the Department of Chemical Engineering in the College of Engineering of the 
King Saud University (Saudi Arabia) where he holds an assistant professor position.

He authored and co-authored around 14 publications mainly in research areas such as Pulsed Electric Field treatment of biological materials such as in pressing, solvent solid liquid extraction, dehydration, etc.

L. Khezami was born in Mjaz El-bab, Tunisia in October of 1973. He received his engineering diploma in industrial chemistry process from the National Engineering School of Gabes (ENIG), and his M.S. and Ph.D. degrees in engineering of industrial processes from the University of Technology of Compiegne (UTC), where he was also a lectureship and research assistant. He also has worked for Afrique Etude Company, Department of Engineering and Study Tunisia, as Engineer project.

$\mathrm{He}$ is currently an assistant professor of Chemistry at Al-Imam Mohamed Ibn Saudi Islamic University (IMAMU), since August 2006. He is the principal investigator of the Industrial and municipal wastewater treatment project of The First Five-Year National Plan for Science, Technology and Innovation in Arabia Saudi Kingdom. His research interests span over several areas related to Environment and pollution treatments, waste water treatment, Kinetic of Pyrolysis, Activated carbon, Adsorption/co-adsorption of Heavy metals, dyes and phenolic products, drying and conservation of food by Osmotic Dehydration and Pulsed Electric Field, etc.

M. K. Hadj-Kali was born in Algeria in 1977. He received his BS degree in chemical engineering, with first class honors, from École Nationale Polytechnique (ENP), Algiers, in 1999. In 2004, He got his PhD degree in chemical engineering from Institut National Polytechnique de Toulouse (INPT), France.

$\mathrm{He}$ worked at École Nationale Superieure des Arts Chimiques Et Technologiques (ENSIACET), Toulouse, from 2004 to 2006 and then he occupied a post-doctoral position from 2006 to 2008 working on the phase equilibria related to the iodine-sulfure thermochemical cycle for hydrogen production.

Dr. Hadj-Kali is currently an assistant professor at King Saud University since 2009. Dr. Hadj-Kali has co-authored more than 20 peer-reviewed journal publications and his research activities are focused on green solvents applications and fluid phase equilibria modeling using methods based on both statistical and classical thermodynamics.

E. Vorobiev was born in Kiev, Ukraine. In 1975 he received the Diploma of engineer, from Technological Institute of Food Industry, National University of Food Industry, Kiev, Ukraine. In 1980 he earned a PhD in technical sciences. Speciality: Process Engineering, National University of Food Industry of Ukraine; and in 1984 the Diploma of senior scientist, High commission of classification of Soviet Union.

His professional experience include: Professor, Department of Process Engineering (former Department of Chemical Engineering), University of Technology of Compiègne, France, 1997 to present; Associated professor, Chemical Engineering Department, University of Technology of Compiègne, France (1995-1997); Contractual lecturer-researcher, Chemical Engineering Department, University of Technology of Compiègne, France (1994-1995) Visiting scientist, Chemical Engineering Department, University of Technology of Compiègne, France (grant of the French Government), 1993; Senior scientist and director of the Laboratory of Separation Processes of the Soviet (then Ukrainian) Research Institute of Sugar Industry (1984-1993); Researcher, then senior scientist of the Soviet Research Institute of Sugar Industry, 1980-1984.; PhD student, Polytechnic Institute of Kiev, Ukraine (1977- 1980); Engineer, UkrNIISP, Kiev, Ukraine (1975- 1977).

He has authored and co-authored about 150 peer reviewed journal papers, written about 5 book chapters and edited 3 books. He held many research and expert position throughout his career and has been part of many scientific organizations. His areas of research include, Filtration, Flocculation, Novel Food Processing techniques such as Pulsed Electric Field treatment of biological materials such as in pressing, solvent solid liquid extraction, etc. 